\title{
THE SEISMIC BEHAVIOUR OF CURTAIN WALLS: AN ANALYSIS BASED ON NUMERICAL MODELLING
}

\begin{abstract}
Mircea BÂRNAURE - Assistant Lecturer, PhD, Technical University of Civil Engineering, Faculty of Civil, Industrial and Agricultural Buildings, e-mail: mircea.barnaure@ponts.org

Mihai VOICULESCU - Professor, PhD, Technical University of Civil Engineering, Faculty of Civil, Industrial and Agricultural Buildings

Abstract: The paper proposes a numerical model to estimate the structural behaviour of a stickbuilt glazed curtain wall system subjected to an imposed displacement of the supports in the plane of the wall. We discuss the role of the parameters that influence on the maximum inter-storey drift corresponding to the service limit state of the wall. The considered parameters are the dimensions of the glazed panel, the gap between the panel and the aluminium frame and the gap between the supports and the mullions. We discuss the problem of remnant deformation of glazed panels, and of misalignment as serviceability criteria. Comparisons are made to laboratory testing results.
\end{abstract}

Keywords: inter-storey drift, glass stress, gap, remnant deformation, in-plane deformation

\section{Introduction}

Past earthquakes, most notably those of Loma Prieta, 1989 [1], Northridge, 1994 [2] and Hyogoken Nanbu, 1995 [3], have indicated that seismic activity may have important effects on the reliability of curtain wall systems. Following these major events, new research programmes have been initiated in countries with high levels of seismicity, such as the US, Japan or New Zeeland, all leading to the creation of rules and provisions for the design and testing of curtain wall systems.

Although the behaviour of curtain walls seems to be more resilient during more recent seismic episodes (Washington, 2001 [4], Chile, 2010 [5]), damages still continue to occur even when earthquakes have a moderate intensity. These structural deteriorations may trigger important economic losses, arising from the disruption of business activity.

The effects of seismic action on curtain wall façades are transmitted through the structure on which they are attached to. The system response is the result not only of inertial forces and shifts triggered by the curtain wall vibration (a direct effect), but is also induced by movements of the areas in which the curtain walls are attached to the building structure (an indirect effect). In the case of conventional buildings, the magnitude of the force associated with the direct effect is much lower than wind loading. Information gathered from the previously mentioned earthquakes indicates that the main deterioration of the curtain wall systems occurs at the level of glazed panels due to the indirect effect of the earthquake.

The seismic behaviour of the curtain walls can be simulated in a laboratory environment. One of the main objectives of the Romanian normative provisions defining the seismic behaviour of curtain walls, which have been established only recently [6], is to use laboratory testing for future enhancements. No standardised rules of seismic testing exist at the European level.

When it comes to the design of curtain wall systems, the conventional approach for projects in areas of high seismic risk is to allow a sufficient gap, equal to the distance of complete separation computed in each direction, between the glazed panels or between the glass panels and the mullions. Such provisions are part of the legal norms for the design of curtain walls introduced in 2005 [7] and further amended in 2006 [8]. 
This represents a cautious approach, given that a physical testing mechanism for the system is not feasible. The relative lack of deterioration of particular curtain walls and glazing under seismic action suggests that more complex movements of the components, with respect to one another and to the main structure, may sometimes protect the framing and the glazed panels from breaking. Hence, the glass panels often have the capability to resist to higher movements than the ones required by the standards without breaking. Higher values as compared to those computed for relative movements are also suggested by laboratory tests [9-13].

The numerical simulations using the finite element method can contribute towards a behavioural analysis of curtain walls under seismic action, while also enabling the researcher to validate laboratory testing results. Furthermore, the numerical simulations allow the identification of the parameters which influence the deformation capacity of the limit state of curtain walls. Lastly, numerical simulations may offer a viable alternative to laboratory testing, which is often difficult and costly.

\section{Simulation Results and Normative Provisions}

One of the pioneering studies addressing the seismic behaviour of curtain walls is the one conducted in 1960 at the University of California [9]. The authors conclude that the type of frame being used significantly influences the seismic behaviour of curtain walls and that the glass panels used in tests have a large movement potential. This movement potential, which may reach a relative inter-storey level of up to $8 \%$, was attributed to the significant space between the mullion and the glass panel that is used in current practice.
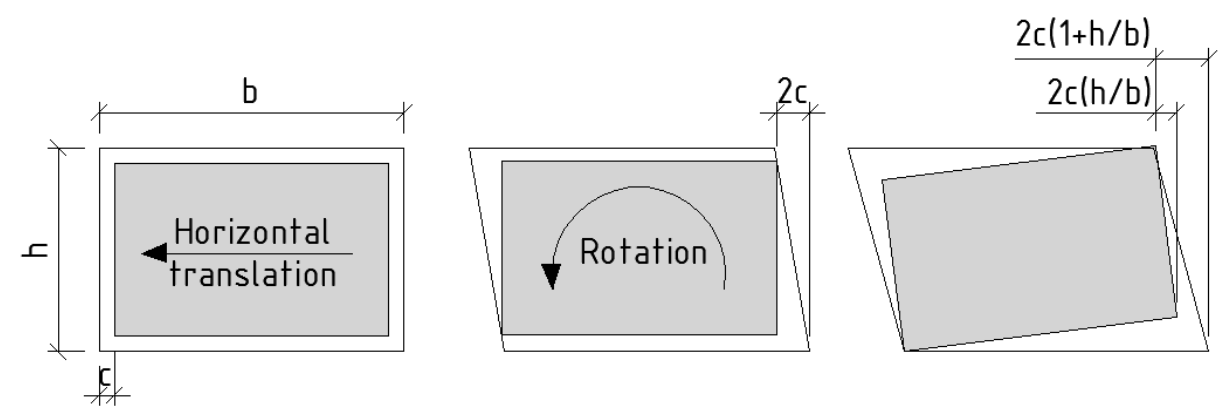

Fig. 1 - The in plane deformation of glazed panels under lateral loadings

The same study also revealed that the in plane deformation of glazed panels under lateral loading takes place in two phases. First, owing to the deformation of its frame, the glass panel is displaced towards the interior of the frame until the opposite corners of the panels adjoin. Next, the glass panel rotates itself until its corners correspond to the adjacent corners of the frame.

The value of the total lateral deformation can be expressed as a function of the dimensions of the panel, the height (h), the width (b) and the free distance between the glass panel and the frame (c):

$$
\Delta=2 c\left(1+\frac{h}{b}\right)
$$

If the horizontal (c1) and vertical (c2) distances of the panel are different, then the above equation becomes:

$$
\Delta=2 c_{1}\left(1+\frac{h c_{2}}{b c_{1}}\right)
$$

According to equations (1) and (2), the ability of a glazed panel to absorb an in plane drift depends not only on the space between the frame and the glass panel, but also on the glass panel dimensions. These relationships are also mentioned in the structural design norms [7-8] that are used for assessing the deformation capacity of glazed panels. 
At the beginning of the 1990s, several tests on glazed curtain wall panels were conducted at the BRANZ laboratories in New Zealand [10]. The primary purpose of this research was to determine the boundaries of the relative drift associated with the ultimate limit state. By relating the results to previous experiments that were conducted on field and corner panels, these tests indicated that evaluating the behaviour of corner panels under seismic action may not be necessary, as such testing would be more costly and complex.

After the Northbridge earthquake in the mid 1990s, subsequent extensive research studying the behaviour of glass panels was carried out at Missouri University of Science and Technology [11] and further developed by scientists at Penn State University [12]. The conclusions of these tests showed that the types of glass and connection systems used have a certain influence on the ultimate limit state.

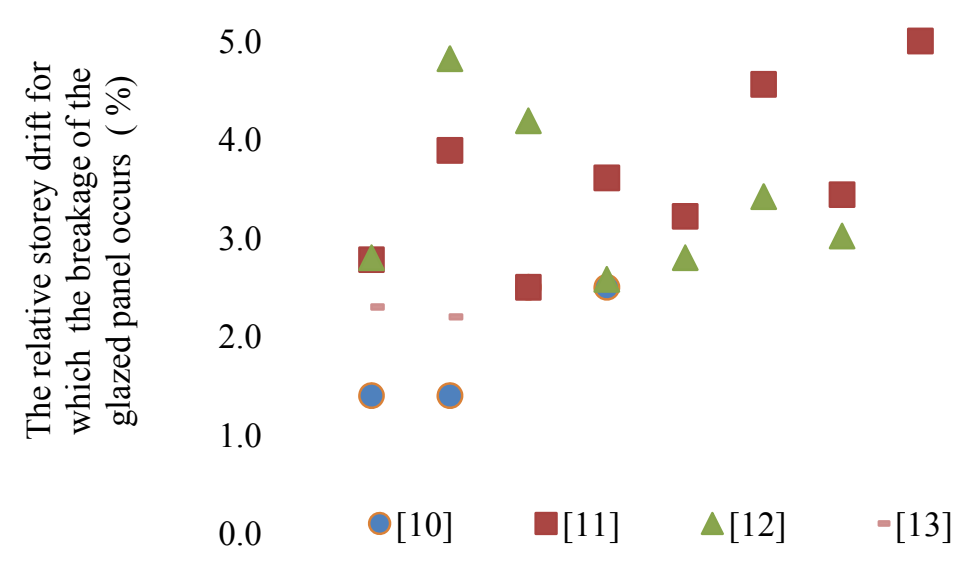

Fig. 2 - Relative storey drift at the limit state according to laboratory tests

In 2009, an experimental study at the University of California [13] indicated that the maximum relative drift of curtain walls is influenced by the panel geometry and the way the loading is applied.

Figure 2 illustrates the values of the relative drift that resulted in the breakage of the glazed panels, as obtained in the recent literature [10-13]. It can be noticed that the data are spread over a large range of values, with substantial differences being observed across studies and even between different samples used in a particular study. Nonetheless, the values are much larger than the likely drift of the core structure at the service limit state, given that the upper limits imposed by legal norms equal $0.5 \%$ [8].

The service limit state is defined as the condition beyond which any extra deterioration requires that the system be rehabilitated. One of the most vulnerable elements of curtain walls is the glazed panel, as the service limit state is often associated with overstepping its resistance capacity.

\section{Model Description}

The numerical model we propose allows the analysis of the curtain wall behaviour when subjected to relative storey drifts in its own plane. The curtain wall panel is included in the model along the height of a storey and incorporates support elements, the frame and the glazed panels.

In order to analyse the role played by the glazed element geometry in influencing the deformation capability, we considered two adjacent curtain wall panels. One of them was divided using an intermediate horizontal transom.

The mullions were considered fixed in the upper and lower parts. To simplify the model, we considered that the support elements are perfectly rigid, although drifts of the mullions supports - along the plane of the wall - are still possible. The connections between the transom and the mullions were considered to be perfectly rigid. 
Not only the curtain wall system frame (the mullions and the transoms), but also the support elements are made of aluminium alloy of type $6063 \mathrm{~T} 5$. The mechanic properties of this material are presented in table 1 .

Table 1

The mechanical properties of aluminium

\begin{tabular}{|l|l|}
\hline \multicolumn{1}{|c|}{ Property } & Notation and values \\
\hline Density & $\rho=2700 \mathrm{~kg} / \mathrm{m}^{3}$ \\
\hline Modulus of elasticity & $\mathrm{E}=70000 \mathrm{~N} / \mathrm{mm}^{2}$ \\
\hline Tangent modulus of elasticity & $\mathrm{G}=27000 \mathrm{~N} / \mathrm{mm}^{2}$ \\
\hline Poisson Coefficient & $v=0,30$ \\
\hline Conventional strength & $\mathrm{f}_{0}=110 \mathrm{~N} / \mathrm{mm}^{2}$ \\
\hline Ultimate strength & $\mathrm{f}_{\mathrm{u}}=160 \mathrm{~N} / \mathrm{mm}^{2}$ \\
\hline
\end{tabular}

Since the shape of extruded sections utilised in current practice is fairly complicated, another simplifying assumption made in the model concerns the mullion and the transom sections, which are assumed to be rectangular with equivalent rigidity. In the analysed design, we considered rectangular mullions $(160 \times 60 \times 4 \mathrm{~mm})$ and rectangular transoms $80 \times 60 \times 4 \mathrm{~mm}$.

We also assumed that the glazed panels are made of a single glass sheet, with a thickness of 15 $\mathrm{mm}$. The mechanic characteristics of the material correspond to those of laminated glass and are indicated in table 2 .

Table 2

The mechanical properties of glass

\begin{tabular}{|l|l|}
\hline \multicolumn{1}{|c|}{ Property } & Notation and values \\
\hline Density & $\rho=2500 \mathrm{~kg} / \mathrm{m}^{3}$ \\
\hline Modulus of elasticity & $\mathrm{E}=70000 \mathrm{~N} / \mathrm{mm}^{2}$ \\
\hline Tangent modulus of elasticity & $\mathrm{G}=28000 \mathrm{~N} / \mathrm{mm}^{2}$ \\
\hline Poisson Coefficient & $v=0,30$ \\
\hline Ultimate strength & $\mathrm{f}_{\mathrm{u}}=22,5 \mathrm{~N} / \mathrm{mm}^{2}$ \\
\hline
\end{tabular}

The computational model is designed using SAP2000 software. For implementation purposes, two materials are defined - aluminium and glass - with the mechanic properties presented before. The representations of propping devices, mullions and of the glazed panel are based on shelltype elements. The discretization grid is dense in the corner areas and rarer in the central area. The computational model is presented in figure 3. Colours are used to distinguish between different section types.

In order to represent as accurately as possible the typical geometry of extruded aluminium frames, we consider that the mullions and transoms have a $6 \mathrm{~mm}$ thick protuberance in their axis which is defined as a shell element. Glass panels are fixed between these protuberances.

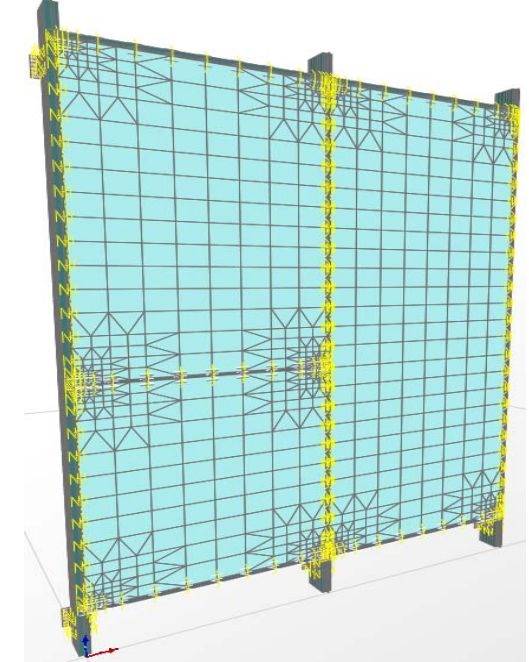

a. View from the outside

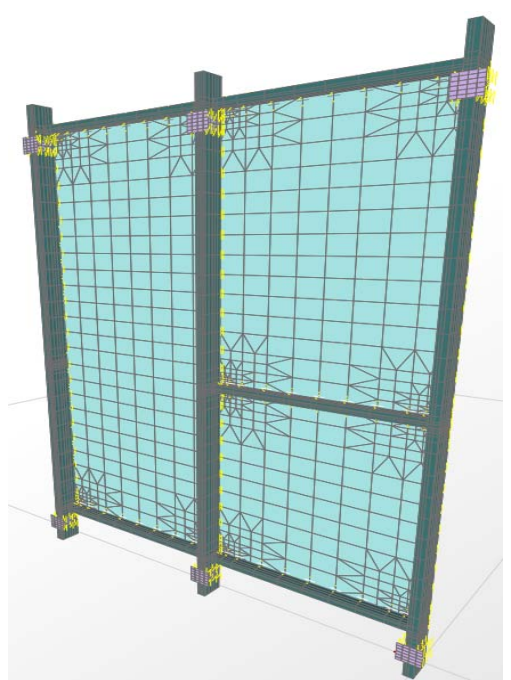

b. View from the inside

Fig. 3 - The geometry of the computational model 
The supports are modelled using shell elements as 10 and $15 \mathrm{~mm}$ thick aluminium plates. The first simulations have shown that the deformation of the supports leads to differences of up to $15 \%$ in the results. For this reason, in order to establish only the influence of the considered parameters, the supports are considered as being perfectly rigid, whereas the movement of the points corresponding to the support is ruled out.

Figure 4 presents a close-up view of the corner area of the panel, near one of the supports. The protuberances between which the glass panel is fixed are displayed in red along the axes of the frame.

The connections between the glass panel and the frames and between the frames and between the supports and the mullions are modelled as link elements. Three types of elements are used: nonlinear gap elements, perfectly rigid elements and nonlinear plastic wen elements.

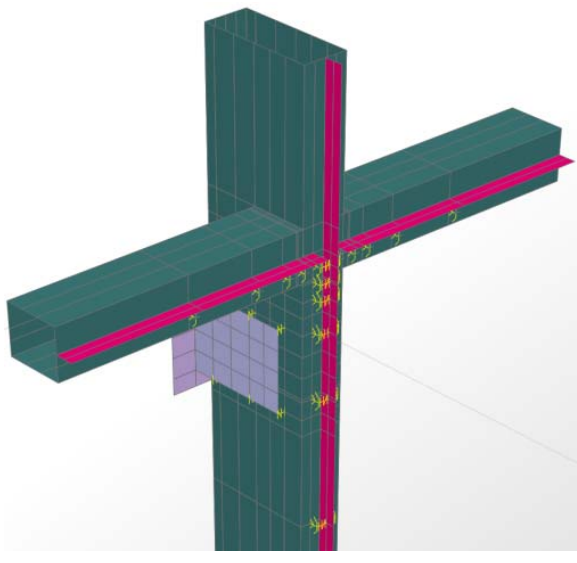

Fig. 4 - Corner area near one of the supports

Fixing of glass panels in the direction perpendicular to their plane is modelled by a wen element noted as FG. To simplify the model, these elements are defined as perfectly rigid in the longitudinal direction so that the distance between the edges of the glass and the frame does not change during the loading period. In the transverse direction, FG elements are defined as nonlinear elastic - perfectly plastic. The stiffness and the yield point values are estimated based on the values for the coefficients of friction between glass and neoprene and elastic modulus of the gasket, available in the technical literature. For the considered model, the stiffness is set at 5 $\mathrm{N} / \mathrm{mm}$, whereas the elastic limit for one element is calibrated at $25 \mathrm{~N}$. This enables the joint movement of the glass panels and the frame, while insuring that negligible stresses are induced in the glazing panel. There is a close similarity between the model-based and the actual behaviour, in which the friction between the glass and gaskets forces the panel to move jointly with the frame. However, the same friction does not prevent the movement or rotation of the window after the corner area contact between the window and the frame takes place.

The connections between the glass panels and the protuberances of the frames as well as between the mullions and the supports are modelled with gap-type links. We defined 4 elements denoted as GJ, GS, GL and GM. The GJ elements are placed between the glass panel and the lower transom, GS between the glass panel and the upper transom, GL between the glass panel and the mullions, and GM between the mullions and the supports. For distances between the linked elements that are higher than the set value, the stiffness of the gap elements is considered null. Conversely, when the distance between the two connected points becomes lower than the set value, the connection is considered perfectly rigid. In this case, the stiffness of the gap element is assigned a value that has an order of magnitude 2-3 higher than that of adjacent elements. The values of the gaps between the glass panels and the frame depend on the curtain wall system used. For usual curtain walls systems, these values range from 3 to $12 \mathrm{~mm}$ [14].

The configuration we have just described prevents the glass panel from interacting with the mullions, if the latter are subject to deformation in the plane of the façade that is lower than a certain critical level. An identical behaviour equally applies to the interaction between the mullions and the support systems.

The simulation of the indirect effect of seismic action is achieved as follows. First, a load pattern is defined where a displacement in the plane of the panels for the upper supports is imposed. The maximum displacement considered in the model has a level of $100 \mathrm{~mm}$. 


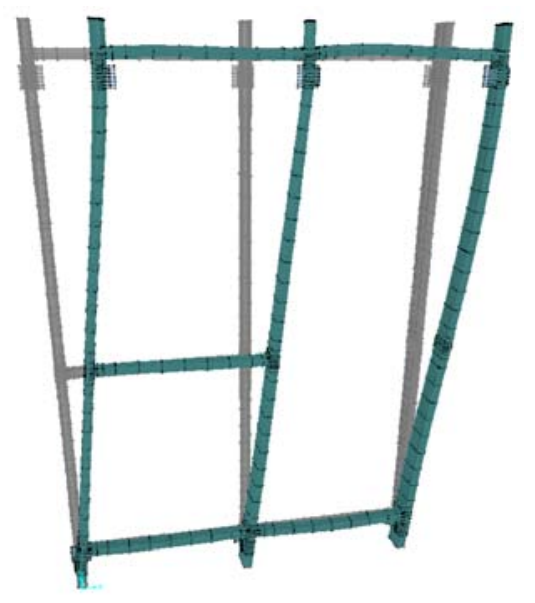

Fig.5 - Deformed shape of the structural framing
Next, a nonlinear static analysis is performed while assuming that the load is applied in 25 equal steps. When the imposed displacement takes place, we also assume that the only load acting on the curtain wall is due to self weight. Finally, a load pattern in which the support systems return to their original position is defined.

In Figure 5 the deformed shape of the structural framing at the maximum imposed displacement is shown. Notice that the deformation does not only occur in the plane of the panel, but also at the level of mullions and transoms, which both display out of plane rotations and deformations.

\section{Results Based on Numerical Simulation}

The model-based results are consistent with those obtained in laboratory tests. It is important that the model implications for the stresses occurring in the glass panels be emphasised. These have minimal initial values up to the point where contact occurs between the glass panel and the aluminium frames. From this point, stresses in the glass panels evolve rapidly. The evolution of the stresses is shown in Figure 6. The initial gap is first closed for the $148 \times 380 \mathrm{~cm}$ panel, and then, almost simultaneously, for the $148 \times 220 \mathrm{~cm}$ and $148 \times 160 \mathrm{~cm}$ panels. This behaviour corresponds to the estimates made using relation (2).
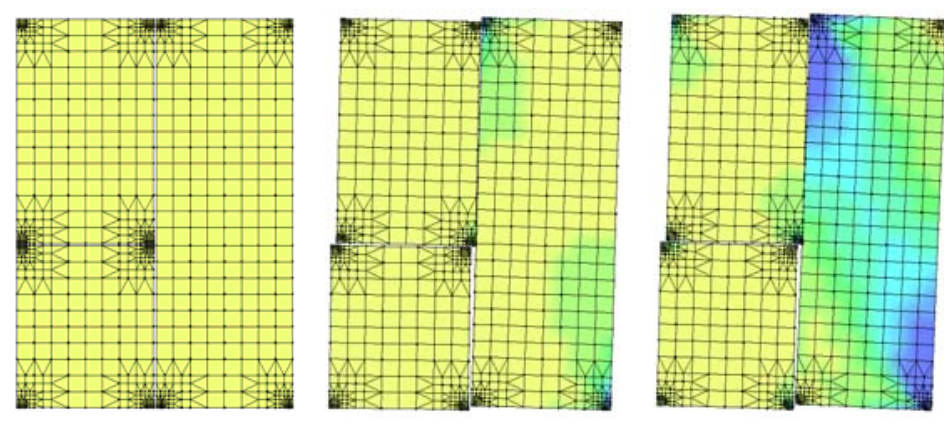

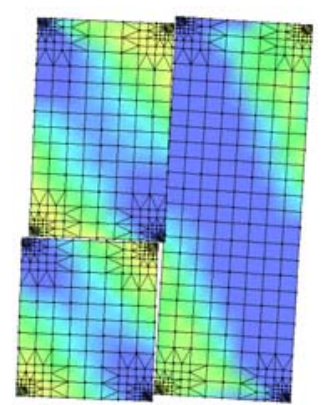

Fig. 6 - Evolution of the stresses in the glass panels

The rapid evolution of stresses after the gap is closed is also observed in the aluminium members. In Figure 7 we show the main stresses that develop in glass and aluminium frames in three load steps: before contact, after contact and three steps after contact. Even though the initial efforts are virtually zero, strains occur after contact in the corners of the glass panel and in the aluminium members. Notice that the value of the stresses rises rapidly if an additional displacement is imposed.
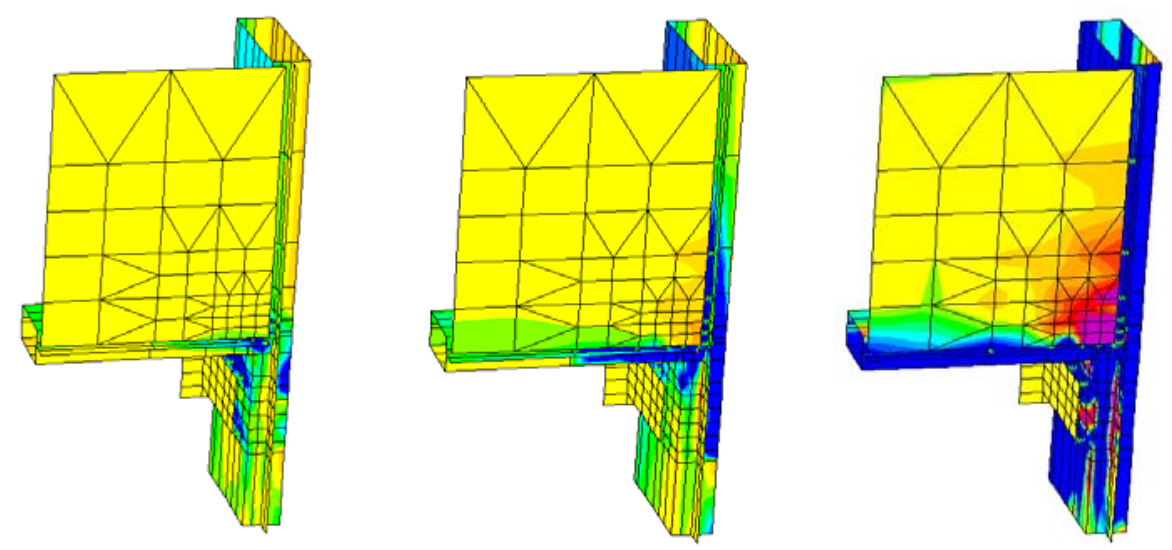

Fig. 7 - Evolution of the stresses after the gap is closed 
The model allows the estimation of the inter-storey drift that triggers the breakage of glass panels. We computed the value of this displacement for several combinations of the GS and GL parameters, while imposing a null GM value. Under the same assumptions we calculated the maximum displacement according to relation (2). In Figure 8 we plot the ratio between the measured and calculated values for 12 pairs of GS - GL values.

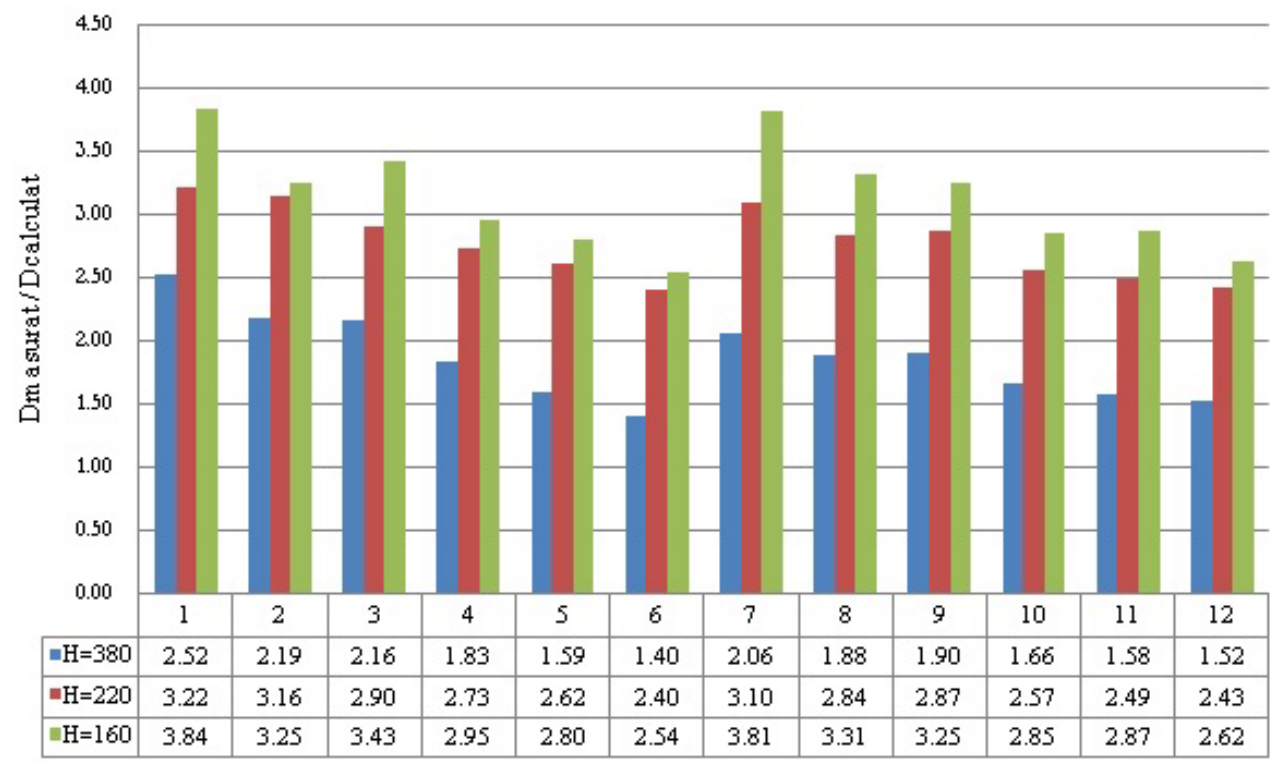

Fig. 8 - Ratio between the relative displacements for serviceability limit state determined on the bases of the model and the relative displacements computed using relation (2)

Notice that the model predicts values for the deformation capacity that are from 1.4 to 3.8 times higher than those estimated based on relation (2) and that, for each pair of the GL GS parameters, the increase is higher when the panel size is small. These important differences are consistent with experimental test results and can be explained by the fact that the model takes into account the deformation of the panel out of the plane and the deformations near the supports, which are not taken into account in the simplified dimensioning formula.

Finally, the model allows the determination of remnant deformation of glazed panels. This phenomenon was observed for laboratory testing [10], as well as during earthquakes [3].

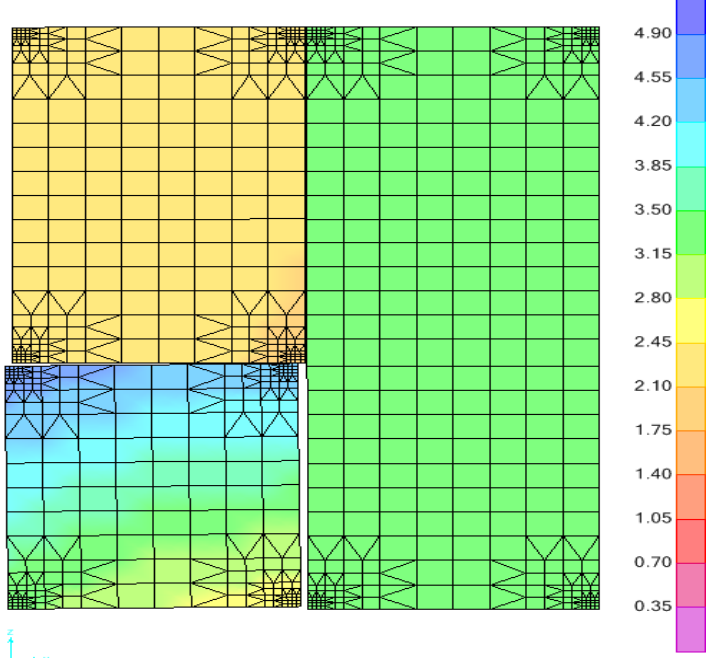

Fig. 9 - Remnant deformations of glazed panels

It has been observed that the misalignment of glass panels can take place for deformations that are 2 to 3 times lower than those causing the breaking of glass [10]. Thus, this parameter may be even a criterion for reaching the service limit state, if the specifications on the façade impose deformation limits.

\section{Conclusions}

The proposed numerical model allows simulating the behaviour of glazed curtain walls subjected to seismic action. The model takes into account the main parameters influencing the deformation capability: size of the glass panels, stiffness of the framing elements, gaps between the supports or the glazed panels and the aluminium frame. 
From both a qualitative and quantitative perspective, the behaviour of the model is consonant with the results obtained in laboratory tests. The similarities refer not only to the phase when the loading is applied, but also to the remnant deformations. The proposed model can therefore be used to complement laboratory tests for stick-built glazed curtain wall systems or may even serve as a functional alternative to testing.

\section{References}

[1] Earthquake Engineering Research Institute (1990). Loma Prieta earthquake reconnaissance report. Earthquake Spectra Vol. 6(1)

[2] Earthquake Engineering Research Institute (1995). Northridge earthquake reconnaissance report. Earthquake Spectra Vol. 11(2)

[3] Earthquake Engineering Research Institute (1995). The Hyogo-ken Nanbu Earthquake January 17, 1995: Preliminary Reconnaissance Report. Earthquake Engineering Research Institute Report Nr. 95-04

[4] Earthquake Engineering Research Institute (2001). The Nisqually, Washington, Earthquake February 28, 2001: Preliminary Reconnaissance Report. Earthquake Engineering Research Institute Report Nr. 2001-01

[5] Earthquake Engineering Research Institute (2010). The Mw8.8 Chile Earthquake of February 27, 2010, Earthquake Engineering Research Institute Special Earthquake Report, 2010

[6] ST-035-2000. Specificaţie tehnică privind cerinţe şi criterii de performanţă pentru verificarea antiseismică a faţadelor cortină

[7] NP 102 - 2004. Normativ pentru proiectarea şi montajul pereţilor cortină pentru satisfacerea cerinţelor de calitate prevăzute de Legea nr. 10/1995

[8] P100-1/2006. Cod de proiectare seismică - Partea I - Prevederi de proiectare pentru clădiri

[9] Bouwkamp, J. G. (1960). Behaviour of window panels under in-plane forces. Structures Material Research Series, University of California, Berkeley, California

[10]Lim, K.Y.S., King, A.B. (1991). The Behaviour of External Glazing Systems Under Seismic In-Plane Racking. Building Research Association of New Zealand Report No. 39

[11]Behr,R.A, Belarbi,A. (1996). Seismic test methods for a rchitectural glazing systems. Earthquake Spectra, Vol. 12

[12]Behr,R.A. (1998) Seismic Performance of Architectural Glass in Mid-Rise Curtain Wall. Journal of Architectural Engineering, Vol. 4(3)

[13] Hutchinson, T.C., Eva, C. (2009). Experimental evaluation of the in-plane seismic behavior of store-front window systems. University of California, San Diego La Jolla

[14] Schüco International KG (2009). Product catalogue. www.schueco.com 